\title{
Interdisciplinary project-based learning: technology for improving student cognition
}

\author{
Natalia Stozhko*, Boris Bortnik, Ludmila Mironova, Albina Tchernysheva and \\ Ekaterina Podshivalova
}

Ural State University of Economics, Yekaterinburg, Russia

(Received 17 February 2015; final version received 8 October 2015)

\begin{abstract}
The article studies a way of enhancing student cognition by using interdisciplinary project-based learning (IPBL) in a higher education institution. IPBL is a creative pedagogic approach allowing students of one area of specialisation to develop projects for students with different academic profiles. The application of this approach in the Ural State University of Economics resulted in a computer-assisted learning system (CALS) designed by IT students. The CALS was used in an analytical chemistry course with students majoring in Commodities Management and Expertise ('expert' students). To test how effective the technology was, the control and experimental groups were formed. In the control group, learning was done with traditional methods. In the experimental group, it was reinforced by IPBL. A statistical analysis of the results, with an application of Pearson $\chi^{2}$ test, showed that the cognitive levels in both IT and 'expert' experimental groups improved as compared with the control groups. The findings demonstrated that IPBL can significantly enhance learning. It can be implemented in any institution of higher or secondary education that promotes learning, including the CALS development and its use for solving problems in different subject areas.
\end{abstract}

Keywords: higher education; learning technology; computer-assisted learning; cognitive level

\section{Introduction}

Extensive literature describes complex engineering, technical, research, educational and social projects whose design and development are based on cross-disciplinary knowledge and that are run by interdisciplinary teams (Carpenter et al. 2007; Goff et al. 2006; Maxim 2006; Piunno et al. 2014; Pooley et al. 2014; Shea et al. 2008; Stetter et al. 2006; Whitney 2014; Yan, Prodanovic, and Taheri 2014). Some authors (Alshara and Ibrahim 2007; Loncar-Vickovic et al. 2012; Rabb, Rogers, and Chang 2008) focus on cooperative learning of students with mixed subject specialism. They suggest that this organisational structure is important, allowing the interdisciplinary team to synchronise their efforts, each contributing their individual strengths and resources to promote student learning. Student involvement into interdisciplinary practical and research activities is not limited by carrying out some work supervised by teachers or specialists. These authors report that project work helps students to overcome some

*Corresponding author. Email: sny@usue.ru

Responsible Editor: Meg O’Reilly, Southern Cross University, Australia.

Research in Learning Technology 2015. C 2015 N. Stozhko et al. Research in Learning Technology is the journal of the Association for Learning Technology (ALT), a UK-based professional and scholarly society and membership organisation. ALT is registered charity number 1063519 . http://www.alt.ac.uk/. This is an Open Access article distributed under the terms of the Creative Commons Attribution 4.0 International License (http://creativecommons.org/licenses/by/4.0/), allowing third parties to copy and redistribute the material in any medium or format and to remix, transform, and build upon the material for any purpose, even commercially, provided the original work is properly cited and states its license. 


\section{N. Stozhko et al.}

barriers erected by disciplinary egocentrism. It develops creativity and enables a balance in student independent learning. This is essential both for problem solution and effective learning and teaching (Mc Goldrick et al. 2013; Rahal 2008; Ramos, Lozano, and Caldero Én 2014; Richter and Paretti 2009; Tan et al. 2006). An intensive development of STEM (science, technology, engineering and math) and STEAM (science, technology, engineering, art and math) education has been recently articulated (Donohue, Hunter, and Richards 2012; Schaffer et al. 2012; Tseng et al. 2013).

The issue of interdisciplinary integration in professional education pursues both a radical restructuring of the whole learning process by constructing a model of an innovative education institution, and the introduction of modern pedagogical methodologies and techniques and IT (Chu et al. 2010; Crampton, Ragusa, and Cavanagh 2012; Di Blas et al. 2014; Gendjova and Yordanova 2009; Sampson et al. 2014).

Different subject areas may make use of various software applications. These differences encourage science teachers and students to collaborate with IT specialists. This collaboration may take a variety of forms: cooperation between departments and academic staff (Chang and Lee 2010; Gaynor and Brown 2012), interdisciplinary computing classes (Carter 2014), using open-source electronic platforms to enhance technology-oriented training of students (Urban 2014). Among these forms a prominent place belongs to interdisciplinary project-based learning (IPBL).

Project-Based Learning (PBL) is an educational process, where learners led by the teacher are motivated to gain knowledge, understanding and skills. Learners are actively involved in the learning process by developing projects related to the solution of practically important issues. For many years in university practice, project development has been used as a form of student final assessment.

Findings of pedagogical research reflect the fact that PBL arouses student interest in the subject course, enhances student motivation and engagement in the learning process, and eventually improves levels of cognition (Johnson and Delawsky 2013). Interdisciplinary collaboration may have different applications in the university class. Barak and Dori (2005) described the integration of PBL in an IT environment into three undergraduate chemistry courses, each including both experimental and control students. Students in the experimental group volunteered to carry out an individual IT-based project, whereas the control students solved only traditional problems. The results indicated that incorporating IT-rich project-based learning can enhance students' understanding of chemical concepts and theories. Dekhane and Tsoi (2010) devised a cross-disciplinary 'business' relationship: the software engineering students were 'hired' by the students enrolled in an organic chemistry course to design and develop a mobile application in order to help teach some organic chemistry concepts. A system approach proposed by Jehlicka (2010) to teaching programming emphasises the interdisciplinary interconnection between physics, informatics and mathematics, thus contributing to the interdisciplinary nature of programming.

The study by Biasutti and El-Deghaidy, undertaken in 2012 and administered in Egypt and Italy, reported on the use of Wiki as an online didactic tool to develop teachers' professional skills. The results of the study suggest that IPBL (Wikis in this case) can develop knowledge management processes and fulfil student's satisfaction while collaborating in designing interdisciplinary projects. Other studies also support these findings (Biasutti and El-Deghaidy 2014; Butler and Christofili 2014; Martínez, Herrero, and de Pablo 2011; Yueh, Liu, and Lin 2015). IPBL arouses students' 
interest in the subject, increases their motivation and involvement in the learning process, contributes to personal growth, development of critical thinking, ability to work in teams and, ultimately, increases the level of cognition and satisfaction of achieved learning outcomes. To sum up, the literature review demonstrates the need, relevance and importance of different forms of interdisciplinary integration, including IPBL.

In the present study we define IPBL as activities, performed by IT students and supervised by experienced staff members of the Computer Science department and other subject teachers. These activities aim to develop e-learning resources (ELR) of different types targeting the solution of subject specialism issues. IPBL involves the following sequence of activities: understanding of the subject content of the problem, that is, students have to 'immerse' themselves in the discipline area in order to develop a project - ELR; design of an algorithm for the ELR content component; design of an algorithm for the technological component of the ELR interface; design of a code for ELR application software; ELR code checkout; ELR experimental approval in the learning process; ELR post-approval adjustment; ELR introduction in the learning process; ELR maintenance for an academic year; presentation of the findings (conference presentation, article publication, software certification, report writing, etc.). In this interpretation IPBL needs to address specific interdisciplinary problems related to the simulation of processes studied by one discipline with the application of tools from another discipline. From this point of view IPBL is closely linked with problem-based learning. However, if the problem-based approach can be limited to a simple statement of the problem (whose solution may be unknown to the teacher), the project-based learning provides for a specific decision path (which is generally known to the teacher). Students, then, can pursue this path during project work and project-based learning. Thus, IPBL is tied to Bloom's taxonomy of educational objectives as it contributes to students' progression from the basic level (knowledge) to the upper level (creativity) (Pappas, Pierrakos, and Nagel 2013; Stockman and Nyland 2010).

The feature of IPBL described in this work is the fact that the relations between all participants are based on mutual interest in developing professional competence and enhancing learning rather than on business outcomes. The use of IPBL in the Ural State University of Economics (USUE) in Ekaterinburg, Russia, has become possible due to the following factors. USUE educates specialists for various sectors of the economy (trade, food safety, banking, management, marketing, macro- and microeconomics, economics and law, hospitality business, computer engineering, etc.). It means that learning - in line with widespread use of information technologies in the tertiary sector - calls for the development of educational resources (computer-assisted learning technologies, assessment methods, simulation systems, hardware, database, etc.), which might be difficult without advanced programming skills.

The bachelor-degree programme Mathematical Software and Information Systems Administration is in fact a combination of Computer Science and Computer Engineering approaches to learning. The attained level of programming skills allows students to use Borland Delphi, $\mathrm{C}++$, Visual Basic, Microsoft FrontPage, Adobe Flash, Adobe Photoshop, Corral Draw, and multimedia-advanced scripting languages such as JavaScript, jQuery library, PHP - Hypertext Markup Language (HTML) and the formal language of cascading stylesheets CSS, while designing application software. This training aids students in solving serious problems, including those attributed to the development of ELR for various subject areas. In our case the 


\section{N. Stozhko et al.}

development of ELR within the framework of IPBL does not require utilisation of a web-based learning platform like Moodle. Students communicate with each other and the teacher via the group site. The group site is created as part of USUE virtual learning environment and can be accessed via a university portal.

The aim of our study is to consider possibilities of applying the proposed pedagogic approach to IPBL for attaining two complementary objectives, namely: to improve learning of undergraduate students with Mathematical Software and Information Systems Administration specialty (hereinafter referred to as 'IT students') and to enhance performance of students majoring in 'Commodities Management and Expertise' (hereinafter referred to as 'expert students') for whom Computer Science is not a core subject. Thus, the objectives of the work are the learning process monitoring, the statistical analysis of the learning outcomes and the assessment of IPBL impact on student knowledge, understanding and skills.

\section{Methods \\ Materials}

The quality of the learning process and learning outcomes were evaluated by reference to student cognitive levels. The hierarchy of the levels used in this work is based on Bloom's Taxonomy (Bloom 1956), which has been modified to meet the study objectives. The aim of our research was to observe the impact of IPBL on student cognition. To achieve the objectives we considered it possible to use a less detailed revised version of Bloom's taxonomy proposed by Russian researchers but barely known in the international academic world (Bespalko 1993; Maximova 2010). The revised Bloom's taxonomy has four levels of cognition where the six tiers in Bloom's taxonomy are paired: the basic level (knowledge and comprehension), the middle level (application and analysis) and the upper level (synthesis and evaluation). In addition to these three levels the lower level of cognition (identification) was introduced to evaluate poor knowledge. Nowadays, in some countries including Russia, young people demonstrate a decreased level of competence in basic science (Elías 2009; Jerrim and Choi 2014; Kostova 2015; Ogura 2005; PISA 2012). That is why the lower cognitive level can be introduced to describe the 'primary knowledge' that students have about a complex discipline before its study.

At the lower cognitive level students are able to identify or recognise previously learned information and to copy it. However, students need some assistance (e.g. a set of prompts) in order to perform certain actions with this information. At the basic level students are able to independently recall and apply appropriate, previously learned information to typical and familiar situations. At the middle level of cognition students are able to apply previously learned information (or knowledge) to new and unfamiliar situations by breaking down information into parts, or examining it. At the upper level of cognitive learning students are able to apply prior knowledge and skills to combine elements into a pattern that is new, and make a judgment according to a set of criteria. Thus, the revised cognitive domain consists of four tiers: the basic, middle and upper levels show positive learning outcomes; the lower level is not disregarded, but is not considered satisfactory.

To follow the revised Bloom's model, the tests consisted of three groups of tasks. Group 1 included the tasks that required reproduction of acquired knowledge. The tasks in Group 2 focused on application, differentiation and analysis. Group 3 
consisted of integrated tasks of producing new aspects of the knowledge, including cross-disciplinary. Students' achievements were graded as follows: the upper level of cognition $-70 \%$ or greater of tasks completed in all three groups; the middle level of cognition $-70 \%$ or greater of tasks completed in any two of the groups; the basic level of cognition $-70 \%$ or greater of tasks completed in one group (usually Group 1); the lower level of cognition - less than $70 \%$ was gained in any of the three groups of tests (meaning that the material had not been learned). The final exam grade was calculated as the average for three groups of tasks using a 100-point scale.

Testing enabled us to identify the proportion of students who acquired the subject knowledge, understanding and skills at the lower, basic, middle or upper level. This technique resulted in obtaining comparable data and statistically reliable indicators that can characterise the level of cognition in a particular academic discipline.

\section{Ethics}

All students were tested with their consent. They were interested in receiving unbiased and objective evaluation of their cognitive level. Assessment methods and confidentiality were agreed with students. The test questions did not address any privacy issues and posed no risk. Thus, the ethical aspects of testing were implicitly accepted by both students and teachers.

\section{Procedure}

The study had two parts. Each part was further divided into three stages: ascertaining, formative and conclusive. At the ascertaining stage experimental groups were formed and the initial level of students' knowledge was determined. At the formative stage an educational process was carried out in the control (traditional education) and experimental (traditional education in combination with IPBL) groups. At the conclusive stage the statistical analysis of data was performed. The level of cognition for each group of students was assessed at each stage.

Part 1 of the study involved IT students. In the ascertaining stage the control and experimental groups (52 and 44 IT students respectively) were formed in accordance with student academic groups. The main hypothesis put forward in Part 1 of the study stated that IPBL improves the cognitive level of IT students, who are involved in designing interdisciplinary projects, in core modules. The following modules were considered 'core' for IT students: Network IT; Information Systems Administration; Operating Systems; User Environment and Frames; Computer Architecture. Most study hours are allocated to these modules, and their acquisition significantly contributes to professional competence in undergraduates.

In the ascertaining stage we tested whether the initial cognitive levels of IT students fit to the normal distribution. We also tested the homogeneity of the control and experimental groups. For this purpose we analysed the results of the Computer Programming exam which was taken prior to the study of core modules, with an application of Student's $t$-test and Pearson $\chi^{2}$ test for the significance level $\alpha=0.05$. In the conclusive stage and 6 months later, homogeneity/non-homogeneity of the groups was tested with the results of final exams in core subjects (modules). In the formative experiment stage IT students studied core modules. In the control group learning was carried out via traditional methods. In the experimental group traditional methods were combined with the computer-assisted learning system (CALS) in analytical 


\section{N. Stozhko et al.}

chemistry (Stozhko, Tchernysheva, and Mironova 2014). The CALS includes a set of computer-based packages written in Delphi, multimedia-advanced scripting languages such as JavaScript, HTML and the formal language of cascading stylesheets CSS. The CALS contains two sub-systems for laboratory work and independent learning. Facing the challenge of designing software, IT students had to apply the existing professional knowledge and skills as well as to immerse themselves in understanding of certain analytical chemistry concepts.

For statistical analysis of the test results, Pearson $\chi^{2}$ test was applied for the significance level $\alpha=0.05$.

$$
\chi^{2}=\frac{B-A}{k} \cdot \frac{1}{S \sqrt{2 \pi}} \exp \left(\frac{\left(y_{j}-M\right)^{2}}{2 S^{2}}\right),
$$

where $A$ and $B$ - minimum and maximum value of the original sample; $k$-number of distribution intervals, $k=1+3.3 \lg n ; n$ - sample size; $M$ - mean of the original sample; $S$-average squared deviation of the original sample; $y_{\mathrm{j}}$ - middle of $\mathrm{j}$-interval $(j=1,2, \ldots, k)$; degree of freedom, $v=k-3$.

A set of tests was developed in order to determine how many experimental and control IT students had attained a certain cognitive level in each core module.

Part 2 of the research involved 'expert' students who enrolled in the analytical chemistry module as part of their curriculum. The main hypothesis was put forward that the analytical chemistry course (module) coupled with the CALS, designed within the framework of IPBL, enhances the 'expert' students' cognitive level.

The procedure for Part 2 of the experiment was repeated. In the ascertaining stage the control and experimental groups (57 and 46 students respectively) were formed. In the formative stage, 'expert' students studied the analytical chemistry module. In the control group learning was carried out by traditional methods. In the experimental group learning combined traditional methods and CALS.

\section{Results and discussion}

During the 2011-2013 academic years within the framework of IPBL, IT students were working on developing computer programs for the CALS in analytical chemistry, which were certified by the Federal Service for Intellectual Property, Patents and Trademarks of the Russian Federation.

\section{Part 1: findings}

A null statistical hypothesis $H_{0}$ stated that the control and experimental groups of IT students are homogeneous in terms of the level of their initial knowledge of Computer Programming. It is worth mentioning that USUE employs a unified information system that enables student academic performance to be graded on a 100-point scale. The data are entered into academic groups' electronic journals and exam records. Then students are automatically rated by their final grades. This system ensures the transparency of the grading process, reduces the impact of human factor and overall provides unbiased student assessment. The hypothesis $H_{0}$ was tested by analysing the results of the Computer Programming exam which was taken prior to the study of core modules. 
For the degree of freedom $v=n+p-2=94$, the calculated value of Student's $t$-test $\left(T_{\text {cal }}\right)$ was 1.9 , its corresponding table value $\left(T_{\text {tab }}\right)$ was 2 . As the calculated value is lower than the table value, the null hypothesis $H_{0}$ can be accepted as plausible for the significance level $\alpha=0.05$. This, in turn, means that the control and experimental groups of IT students were homogeneous with regard to the results in the Computer Programming exam. In the ascertaining stage a null statistical hypothesis $H_{0}^{(1)}$ was put forward whereby the results of the control and experimental groups in Computer Programming are described as normally distributed. For the significance level $\alpha=0.05, n=96$ and degree of freedom $v=5$, Pearson $\chi^{2}$ test was calculated $\chi_{\text {cal }}^{2}=2.23$. Its corresponding table value was $\chi_{\text {tab }}^{2}=11.1$. As $\chi_{\text {cal }}^{2}<\chi_{\text {tab }}^{2}(2.23<11.1)$, then for the significance level $\alpha=0.05$ and degree of freedom $v=5$, the null statistical hypothesis $H_{0}^{(1)}$ does not contradict the obtained data, that is, the empirical distribution describing the results of the Computer Programming exam can be taken as normal.

In the concluding stage of Part 1 of the experiment, a null statistical hypothesis $H_{0}^{(2)}$ was put forward, whereby IT students in the control and experimental groups are homogeneous in terms of the cognitive levels in core disciplines.

The results in Table 1 show how homogeneous IT students were in the control and experimental groups. The data are based on the results of the tests on core modules obtained in the concluding stage. According to the results, the computed values of Student's $t$-test do not exceed the corresponding table value $\left(T_{\mathrm{tab}}=2.0\right)$, which allows us to accept the hypothesis $H_{0}^{(2)}$ as a plausible statement.

Six months after the completion of the core modules, a null statistical hypothesis $H_{0}^{(3)}$ was put forward, whereby the control and experimental groups of IT students are homogeneous in terms of the cognitive levels in core disciplines and belong to one universal set.

The results of re-testing IT students' knowledge and understanding 6 months after the completion of the core modules are presented in Table 2.

For both, control and experimental, groups the calculated values of $\chi^{2}$ exceed the table values (the control IT group: $k=7 ; v=4 ; \chi_{\text {crit. }}^{2}=9.5$; the experimental IT group: $\left.k=6 ; v=3 ; \chi_{\text {crit. }}^{2}=7.8\right)$. These data allow us to reject the null hypothesis $H_{0}^{(3)}$ in

Table 1. The results of assessing homogeneity of control and experimental IT groups.

\begin{tabular}{llllll}
\hline & \multicolumn{2}{c}{$\begin{array}{c}\text { Control } \\
\text { group, } n=52\end{array}$} & $\begin{array}{c}\text { Experimental } \\
\text { group, } p=44\end{array}$ & \\
\cline { 2 - 5 } & \multicolumn{3}{c}{$v=94 ; T_{\mathrm{tab}}=2$} \\
\cline { 2 - 5 } Modules & $M_{\mathrm{c}}$ & $m_{\mathrm{c}}$ & $M_{\mathrm{e}}$ & $m_{\mathrm{e}}$ & $T_{\text {cal }}$ \\
\hline Network IT & 78.1 & 2.9 & 85.3 & 2.5 & 1.9 \\
Information Systems Administration & 78.8 & 2.6 & 84.9 & 2.8 & 1.6 \\
Operating Systems, User Environment & 80.5 & 2.5 & 86.7 & 2.6 & 1.7 \\
$\quad$ and Frames & 86.8 & 2.0 & 91.9 & 2.1 & 1.7 \\
\hline
\end{tabular}

Note: $M_{\mathrm{c}}$ and $m_{\mathrm{c}}-$ an average exam mark and its error component of the mean in the control group; $M_{\mathrm{e}}$ and $m_{\mathrm{e}}-$ an average exam mark and its error component of the mean in the experimental group; $n$ and $p-$ number of students in the control and the experimental group; $\mathrm{v}$ - degrees of freedom $(v=n+p-2) ; T_{\mathrm{tab}}-$ table value of Student's t-test:

$T_{\text {cal }}$ - calculated value of Student's $t$-test $T_{c a l}=\frac{\left(M_{c}-M_{e}\right)}{\sqrt{m_{c}^{2}-m_{e}^{2}}}$ 
Table 2. The results of re-testing IT students on core modules.

\begin{tabular}{|c|c|c|c|c|}
\hline \multirow[b]{3}{*}{ Core module } & \multirow{2}{*}{\multicolumn{2}{|c|}{$\begin{array}{c}\text { Control group, } \\
n=52 \\
\begin{array}{c}k=7 ; v=4 ; \\
\chi_{\text {crit }}^{2}=9.5\end{array}\end{array}$}} & \multirow{2}{*}{\multicolumn{2}{|c|}{$\begin{array}{c}\text { Experimental group, } \\
p=44 \\
k=6 ; v=3 \\
\chi_{\text {crit }}^{2}=7.8\end{array}$}} \\
\hline & & & & \\
\hline & $M_{\mathrm{c}}$ & $\chi_{\text {cal }}^{2}$ & $M_{\mathrm{e}}$ & $\chi_{\mathrm{cal}}^{2}$ \\
\hline Network IT & 74.1 & 54.3 & 82.2 & 18.2 \\
\hline Information Systems Administration & 70.8 & 62.1 & 80.0 & 16.4 \\
\hline Operating Systems, User Environment and Frames & 78.0 & 53.1 & 84.2 & 14.8 \\
\hline Computer Architecture & 82.3 & 55.2 & 84.6 & 13.6 \\
\hline
\end{tabular}

Note: $\chi_{\text {crit }}^{2}$ - table value of Pearson test; $\chi_{\text {cal }}^{2}$ - calculated value of Pearson test; $k=1+3.3 \lg n$ (or $p$ )

favour of the alternative hypothesis $H_{1}^{(3)}$, whereby the control and experimental groups of IT students are not homogeneous and belong to different universal sets by the level of cognition in all core modules.

Distribution of the experimental and control IT students by cognitive level in core module on the basis of test results is presented in Table 3.

It is apparent from the data in Table 3 that the number of IT students in the experimental group (with IPBL) who achieved the middle and upper levels of cognition in core modules is higher than in the control group with traditional learning. At the same time IT students never demonstrated this lower level at any stage of testing. Table 3 shows that the number of students who attained the middle and upper cognitive levels in each core module is higher in the experimental group as compared with the control group. Table 4 presents a comparative analysis of the cumulative percentage of the control and experimental IT students who attained the middle and upper levels of cognition in core modules.

Thus, the outcomes of Part 1 of the study demonstrate that, on average, $79.5 \%$ of IT students in the experimental group (who combined the study of core modules with IPBL) have achieved the middle and upper levels of cognitive learning, which is 2.3 times higher than the results of the control group. It allows us to conclude that the main hypothesis put forward in Part 1 is a plausible statement. The control and experimental groups, which initially had been practically identical, came to belong to different universal sets by the end of the experiment. Moreover, students in the

Table 3. Distribution of control and experimental IT students by cognitive levels in core modules.

\begin{tabular}{|c|c|c|c|c|c|c|}
\hline \multirow[b]{2}{*}{ Core modules } & \multicolumn{3}{|c|}{ Control group (\%) } & \multicolumn{3}{|c|}{ Experimental group (\%) } \\
\hline & $\begin{array}{l}\text { Basic } \\
\text { level }\end{array}$ & $\begin{array}{l}\text { Middle } \\
\text { level }\end{array}$ & $\begin{array}{l}\text { Upper } \\
\text { level }\end{array}$ & $\begin{array}{l}\text { Basic } \\
\text { level }\end{array}$ & $\begin{array}{l}\text { Middle } \\
\text { level }\end{array}$ & $\begin{array}{l}\text { Upper } \\
\text { level }\end{array}$ \\
\hline Network IT & 65 & 29 & 6 & 15 & 59 & 26 \\
\hline $\begin{array}{l}\text { Information Systems } \\
\text { Administration }\end{array}$ & 62 & 31 & 7 & 24 & 52 & 24 \\
\hline $\begin{array}{l}\text { Operating Systems, User } \\
\text { Environment and Frames }\end{array}$ & 66 & 30 & 4 & 17 & 64 & 19 \\
\hline Computer Architecture & 71 & 24 & 5 & 26 & 53 & 21 \\
\hline
\end{tabular}


Table 4. Cumulative percentage of IT students with the middle and upper cognitive levels in core modules.

\begin{tabular}{lccc}
\hline Core module & $\begin{array}{c}\text { Control } \\
\text { group (\%) }\end{array}$ & $\begin{array}{c}\text { Experimental } \\
\text { group (\%) }\end{array}$ & $\begin{array}{c}\text { Exceeding cognitive } \\
\text { level (times) }\end{array}$ \\
\hline $\begin{array}{l}\text { Network IT } \\
\text { Information Systems }\end{array} \quad 35$ & 85 & 2.4 \\
$\quad$ Administration & 38 & 76 & 2.0 \\
$\begin{array}{l}\text { Operating Systems, User } \\
\text { Environment and Frames }\end{array}$ & 34 & 83 & 2.4 \\
$\begin{array}{l}\text { Computer Architecture } \\
\text { Generalised estimator of the level } \\
\text { of cognition }\end{array}$ & 29 & 74 & 2.5 \\
\hline
\end{tabular}

experimental group demonstrated much better achievements. Thus, IPBL improves the cognitive level of IT students, who are involved in designing interdisciplinary projects.

\section{Part 2: findings}

Testing homogeneity of the control and experimental groups of 'expert' students with regard to their cognitive level in analytical chemistry showed that in the control group $53 \%$ of the students had the basic level, $40 \%$ had the middle level and $7 \%$ had the upper level of cognition. In the experimental group 52\% of the students had the basic level; 39\% the middle level; and 9\% the upper level of cognitive learning. These test results suggest that the control and experimental groups of 'expert' students can be considered homogeneous.

In the ascertaining stage a null statistical hypothesis $H_{0}^{(4)}$ stated that the distribution of 'expert' students' test results in analytical chemistry in both control and experimental groups obeys the normal distribution law. For the significance level $\alpha=0.05, n=103$, and degree of freedom $v=5$, Pearson $\chi^{2}$ test was calculated $\chi_{\text {cal }}^{2}=4.38$. Its corresponding table value was $\chi_{\text {tab }}^{2}=11.1$. As $\chi_{\text {cal }}^{2}<\chi_{\text {tab }}^{2}(4.38<11.1)$, the null statistical hypothesis $H_{0}^{(4)}$ can be accepted as a plausible statement.

The null statistical hypothesis $H_{0}^{(5)}$ about homogeneity of the control and experimental student groups was tested in the conclusive stage (upon the completion of the analytical chemistry course) by calculating Student's $t$-test and was accepted to be true: $t_{\text {cal }}=0.32$, or lower than $t_{\text {crit }}=2.1\left(t_{\text {crit }}>t_{\text {cal }}\right)$. This allows us to accept the null statistical hypothesis $H_{0}^{(5)}$, whereby the control and experimental groups are homogeneous in terms of cognitive levels in analytical chemistry after the completion of the module. Six months later a null statistical hypothesis $H_{0}^{(6)}$ was put forward, whereby the experimental and control groups are homogeneous and belong to one universal set.

Re-testing 'expert' students on analytical chemistry 6 months after the completion of the course showed the following. For the control 'expert' group $(k=7 ; v=4$; $\left.\chi_{\text {crit }}^{2}=9.5\right) \quad \chi_{\text {cal }}^{2}=44.25$. For the experimental group $\left(k=6 ; \quad v=3 ; \chi_{\text {crit. }}^{2}=7.8\right)$ $\chi_{\text {cal }}^{2}=19.62$. For both groups $\chi_{\text {cal }}^{2}$ was always higher than the table values, which allows us to reject the hypothesis $H_{0}^{(6)}$ in favour of the alternative hypothesis $H_{1}^{(6)}$, whereby the control and experimental groups are not homogeneous and belong to different universal sets in terms of levels of cognition in analytical chemistry. The test 


\section{N. Stozhko et al.}

results allowed us to identify the proportion of 'expert' students with the relevant cognitive level in analytical chemistry.

Table 5 summarises the results of comparative analysis of the cognitive level in analytical chemistry for the control and experimental groups of 'expert' students before and after the use of traditional learning and the CALS.

The majority of 'expert' students in the control and experimental groups attained the basic cognitive level and above, while at the beginning of the experiment this proportion was below $50 \%$. Moreover, the students' achievements in the experimental group were much better. The cumulative proportion of 'expert' students in the experimental group, who achieved the basic, middle and upper cognitive levels in analytical chemistry after the use of the CALS, is $90 \%$, which is 1.4 times higher than the results for the control group $(65 \%)$. This allows us to suggest that Part 2 of the main hypothesis is a plausible statement. It should be noted that in the course of training with CALS 'expert' students used enhanced IT skills to be operationally effective in the specialist subject area. Thus, the undertaken study showed the effectiveness of the IPBL approach that was developed and implemented in the learning process in USUE.

\section{Conclusion}

Interdisciplinary integration is one of the general trends in the development of tertiary educational systems worldwide. It meets the demands of the competence approach in teaching and learning and contributes to a higher level of professionalism in graduates. An effective form of interdisciplinary integration is interdisciplinary project-based learning, directly implementing the principles of practice (or context)-based learning. One of the IPBL approaches was developed in the Ural State University of Economics (Russia). It was tested on the groups of students enrolled in the bachelor-degree programs Mathematical Software and Information Systems Administration (IT students) and Commodities Management and Expertise ('expert' students). IPBL is used as part of IT students' research and final qualification work. Computer programs for the CALS in analytical chemistry designed by IT students are used for training 'expert' students.

While working on designing interdisciplinary projects, IT students were able to use core knowledge and skills in the area of specialisation. At the same time they learned how to apply professional competencies to other subject areas, analytical chemistry in particular. Statistical analysis of the pedagogical experiment findings

Table 5. Comparative analysis of cognitive levels in analytical chemistry in control and experimental 'expert' groups.

\begin{tabular}{|c|c|c|c|c|}
\hline \multirow[b]{3}{*}{$\begin{array}{l}\text { Cognitive } \\
\text { level }\end{array}$} & \multicolumn{4}{|c|}{ Proportion of students ( $\%)$} \\
\hline & \multicolumn{2}{|c|}{ Control group } & \multicolumn{2}{|c|}{ Experimental group } \\
\hline & $\begin{array}{l}\text { Before traditional } \\
\text { learning }\end{array}$ & $\begin{array}{l}\text { After traditional } \\
\text { learning }\end{array}$ & $\begin{array}{l}\text { Before } \\
\text { CAL }\end{array}$ & $\begin{array}{l}\text { After } \\
\text { CAL }\end{array}$ \\
\hline Lower & 53 & 35 & 52 & 10 \\
\hline Basic & 40 & 51 & 39 & 60 \\
\hline Middle & 7 & 10 & 9 & 17 \\
\hline Upper & - & 4 & - & 13 \\
\hline
\end{tabular}


has resulted in some quantitative data which show that the use of IPBL has a positive impact on student cognition; namely, the cognitive level in the experimental group of IT students has exceeded the cognitive level in the control group by 2.3 times. For the group of 'expert' students this increase has been 1.4 times.

IPBL promotes the development of a range of both intellectual and practical skills in graduates. Our experiment has demonstrated a positive influence of IPBL on the learning effectiveness in IT students. The projects developed by IT students offered the 'expert' students additional ways of learning the disciplines. IPBL, discussed in the article, can be recommended for use in universities and colleges that have IT programs and promoted using IT projects as part of an educational process in various academic departments.

\section{Acknowledgements}

The research for this paper was financially supported by the Ministry of Education and Science of the Russian Federation, project no. 2940, grant no. 2014/238.

\section{References}

Alshara, O. K. \& Ibrahim, M. (2007) 'Business integration using the interdisciplinary project based learning model (IPBL)', in Human interface and the management of information. Interacting in information environments, eds M. J. Smith \& G. Salvendy, Springer Verlag, Berlin, Part II, pp. 821-833.

Barak, M. \& Dori, Y. J. (2005) 'Enhancing undergraduate students' chemistry understanding through project-based learning in an IT environment', Science Education, vol. 89, no. 1, pp. $117-139$.

Bespalko, V. P. (1993) 'Standardization of education: basic ideas and concepts', Pedagogy, vol. 5, pp. 16-25. [Russian].

Biasutti, M. \& El-Deghaidy, H. (2012) 'Using Wiki in teacher education: impact on knowledge management processes and student satisfaction', Computers \& Education, vol. 59, pp. $861-872$

Biasutti, M. \& El-Deghaidy, H. (2014) 'Interdisciplinary project-based learning: an online wiki experience in teacher education', Technology, Pedagogy and Education, [online] Available at: http://2014.899510

Bloom, B. S., et al., (eds) (1956) Taxonomy of Educational Objectives. The Classification of Educational Goals. Handbook 1: Cognitive Domain, Longmans, Green \& Co. Ltd, London.

Butler, A. \& Christofili, M. (2014) 'Project-based learning communities in developmental education: a case study of lessons learned', Community College Journal of Research and Practice, vol. 38, no. 7, pp. 638-650.

Carpenter, S. L., et al., (2007) 'A knowledge modeling approach to evaluating student essays in engineering courses', Journal of Engineering Education, vol. 96, no. 3, pp. 227-239.

Carter, L. (2014) 'Interdisciplinary computing classes: worth the effort', SIGCSE Technical Symposium on Computer Science Education, 5-8 March 2014, Atlanta, GA, pp. 445-450.

Chang, L.-C. \& Lee, G. C. (2010) 'A team-teaching model for practicing project-based learning in high school: collaboration between computer and subject teachers', Computers and Education, vol. 55, no. 3, pp. 961-969.

Chu, H.-C., Hwang, G.-J. \& Tsai, C.-C. (2010) 'A knowledge engineering approach to developing mind tools for context-aware ubiquitous learning', Computers and Education, vol. 54, no. 1, pp. 289-297.

Crampton, A., Ragusa, A. T. \& Cavanagh, H. (2012) 'Cross-discipline investigation of the relationship between academic performance and online resource access by distance education students', Research in Learning Technology, vol. 20, no. 1, p. 14430.

Dekhane, S. \& Tsoi, M. Y. (2010) 'Work in progress - Inter-disciplinary collaboration for a meaningful experience in a software development course', Proceedings - Frontiers in 


\section{N. Stozhko et al.}

Education Conference: Celebrating Forty Years of Innovation, 27-30 October 2010, Arlington, VA, 5673103, pp. S1D1-S1D2.

Di Blas, N., et al., (2014) 'A portal of educational resources: providing evidence for matching pedagogy with technology', Research in Learning Technology, [online] Available at: http:// www.researchinlearningtechnology.net/index.php/rlt/article/view/22906

Donohue, S. K., Hunter, W. G. S. \& Richards, L. G. (2012) 'Special session: raising P-20 engineers - nurturing creativity and curiosity by getting STEAMd', Proceedings - Frontiers in Education Conference, 3-6 October 2012, Seattle, WA, 6462473.

Elías, C. (2009) 'The decline of natural sciences: confronting diminishing interest, fewer scientists and poorer working conditions in western countries. A comparative analysis between Spain and the United Kingdom', Papers: Revista de Sociologia, papers 93, pp. 69-79, [online] Available at: http://www.raco.cat/index.php/Papers/article/view/140570/191801

Gaynor, J. W. \& Brown, D. (2012) 'An online booking system encourages self-directed learning and personalization of study', Journal of Chemical Education, vol. 89, no. 8, pp. 1019-1024.

Gendjova, A. \& Yordanova, B. (2009) 'Project-based learning in science at the American College of Sofia', Chemistry, vol. 18, no. 4, pp. 255-267.

Goff, R. M., et al., (2006) 'Evolution of student perception in a human centered interdisciplinary design project', Proceedings - Frontiers in Education Conference, FIE, 28-31 October 2006, San Diego, CA, 4117082.

Jehlicka, V. (2010) 'Interdisciplinary relations in teaching of programming', Applied Computing Conference, (ACC'10), 21-23 October 2010, Timisoara, Romania, pp. 33-38.

Jerrim, J. \& Choi, A. (2014) 'The mathematics skills of school children: how does England compare to the high-performing East Asian jurisdictions?', Journal of Education Policy, vol. 29 , no. 3 , pp. $349-376$.

Johnson, C. S. \& Delawsky, S. (2013) 'Project-based learning and student engagement', Academic Research International, vol. 4, no. 4, pp. 560-570.

Kostova, Z. (2015) 'Anxiety in science education', Chemistry, vol. 24, no. 1, pp. 20-57 [Bulgarian].

Loncar-Vickovic, S., et al., (2012) 'Student workshops in engineering education: case studies at the Faculty of Civil Engineering in Osijek, Croatia', International Journal of Engineering Education, vol. 28, no. 4, pp. 845-851.

Maxim, B. R. (2006) 'Work in progress: use of interdisciplinary teams in game development classes', Proceedings - Frontiers in Education Conference, FIE, 28-31 October 2006, San Diego, CA, 4117095.

Mc Goldrick, N. B., et al., (2013) 'Implementing a multidisciplinary program for developing learning, communication, and team-working skills in second-year undergraduate chemistry students', Journal of Chemical Education, vol. 90, no. 3, pp. 338-344.

Martínez, F., Herrero, L. C. \& de Pablo, S. (2011) 'Project-based learning and rubrics in the teaching of power supplies and photovoltaic electricity', IEEE Transactions on Education, vol. 54, no. 1, pp. 87-96.

Maximova, V. N. (2010) 'Acmeological technology in school - the teacher', Scientific support of advanced training, vol. 4, no. 2, pp. 5-10 [Russian].

Ogura, Y. (2005) 'Situation and problems of decrease of Japanese students in Science and Technology fields', OECD/Japan Seminar, June 23-24, Tokyo, [online] Available at: http:// www.aspacnet.org/apec/research/_pdfs/OECDJapanSeminarOgura050624.pdf

Pappas, E., Pierrakos, O. \& Nagel, R. (2013) 'Using Bloom's Taxonomy to teach sustainability in multiple contexts', Journal of Cleaner Production, vol. 48, pp. 54-64.

Piunno, P. A. E., et al., (2014) 'The advanced interdisciplinary research laboratory: a student team approach to the fourth-year research thesis project experience', Journal of Chemical Education, vol. 91, no. 5, pp. 655-661.

'PISA 2012 results: which country does best at reading, maths and science?' [online] Available at: http://www.theguardian.com/news/datablog/2013/dec/03/pisa-results-country-best-reading-maths-science

Pooley, S. P., Mendelsohn, J. A. \& Milner-Gulland, E. J. (2014) 'Hunting down the chimera of multiple disciplinarity in conservation science', Conservation Biology, vol. 28, no. 1, pp. 22-32.

Rabb, R., Rogers, J. \& Chang, D. (2008) 'Course development in interdisciplinary controls and mechatronics', Proceedings - Frontiers in Education Conference, 22-25 October 2008, Saratoga Springs, NY, 4720525, pp. T3F11-T3F15. 
Rahal, I. (2008) 'Undergraduate research experiences in data mining', SIGCSE'08 Proceedings of the 39th ACM Technical Symposium on Computer Science, 12-15 March 2008, Portland, OR, pp. 461-465.

Ramos, J. F., Lozano, J. J. F. \& Caldero Én, A. G. (2014) 'Design of electric racing vehicles: an experience of interdisciplinary project-based education in engineering', EVS 2014 Proceedings of the 27th World Electric Vehicle Symposium and Exhibition, 17-20 November 2013, Barcelona, Spain, 6914899

Richter, D. M. \& Paretti, M. C. (2009) 'Identifying barriers to and outcomes of interdisciplinarity in the engineering classroom', European Journal of Engineering Education, vol. 34, no. 1, pp. 29-45.

Sampson, D. G., et al., (2014) 'Digital systems supporting cognition and exploratory learning in 21st century', Knowledge Management and E-Learning, vol. 6, no. 2, pp. 98-102.

Schaffer, S. P., et al., (2012) 'Team learning developing interdisciplinary project teams', Proceedings - Frontiers in Education Conference, 3-6 October 2012, Seattle, WA, 6462513.

Shea, K., et al., (2008) 'Teaching an integrated new product development seminar on cognitive products', Proceedings DESIGN 2008, the 10th International Design Conference, 19-22 May 2008, Dubrovnik, Croatia, pp. 1401-1408.

Stetter, R., et al., (2006) 'Teaching "coupling competence" by means of interdisciplinary projects', 9th International Design Conference, DESIGN 2006, 15-18 May 2006, Dubrovnik, Croatia, pp. 1267-1274.

Stockman, M. \& Nyland, J. (2010) 'A teaching pedagogy for networking/system administration courses: freshman through senior years', SIGITE'10 - Proceedings of the 2010 ACM Conference on Information Technology Education, 7-9 October 2010, Midland, MI, USA, pp. 15-19.

Stozhko, N. Y., Tchernysheva, A. V. \& Mironova, L. I. (2014) 'Computer assisted learning system for studying analytical chemistry', Chemistry: Bulgarian Journal of Science Education, vol. 23, no. 4, pp. 607-613.

Tan, J. K., et al., (2006) 'Development of an interdisciplinary design curriculum: preparing the students for final year major design projects', DS 38: Proceedings of E and DPE 2006, the 8th International Conference on Engineering and Product Design Education, 7-8 September 2006, Salzburg, Austria, pp. 33-38.

Tseng, K.-H., et al., (2013) 'Attitudes towards Science, Technology, Engineering and Mathematics (STEM) in a Project-Based Learning (PjBL) Environment', International Journal of Technology and Design Education, vol. 23, no. 1, pp. 87-102.

Urban, P. L. (2014) 'Open-source electronics as a technological aid in chemical education', Journal of Chemical Education, vol. 91, no. 5, pp. 751-752.

Whitney, M. C. (2014) 'Interdisciplinary collaboration in the classroom', International Journal of Interdisciplinary Studies in Communication, vol. 8, no. 4, pp. 1-8.

Yan, C. Y., Prodanovic, V. \& Taheri, R (2014) 'Engineering students' perception of project based learning activities at the school of engineering, UBC Okanagan campus', Proceedings of the 121st ASEE Annual Conference and Exposition: 360 Degrees of Engineering Education, Indianapolis, IN; US, 8395, [online] Available at: http://www.asee.org/public/conferences/ 32/papers/8395/view

Yueh, H.-P., Liu, Y.-L. \& Lin, W. (2015) 'Fostering interdisciplinary learning in a smart living technology course through a PBL approach', International Journal of Engineering Education, vol. 31, no. 1, pp. 220-228. 